\title{
Corpo e Velhice: Um Estudo das Representações Sociais entre Homens Idosos
}

\author{
Body and Old Age: \\ A Study of the Social Representations Among \\ Cuerpo Y Vejez: \\ Un Estudio de las Representaciones \\ Sociales entre Hombres Mayores
}

Ludgleydson Araújo,

Elba Celestina do Nascimento

Sá \& Edna de Brito Amaral

Universidade Federal do Piauí
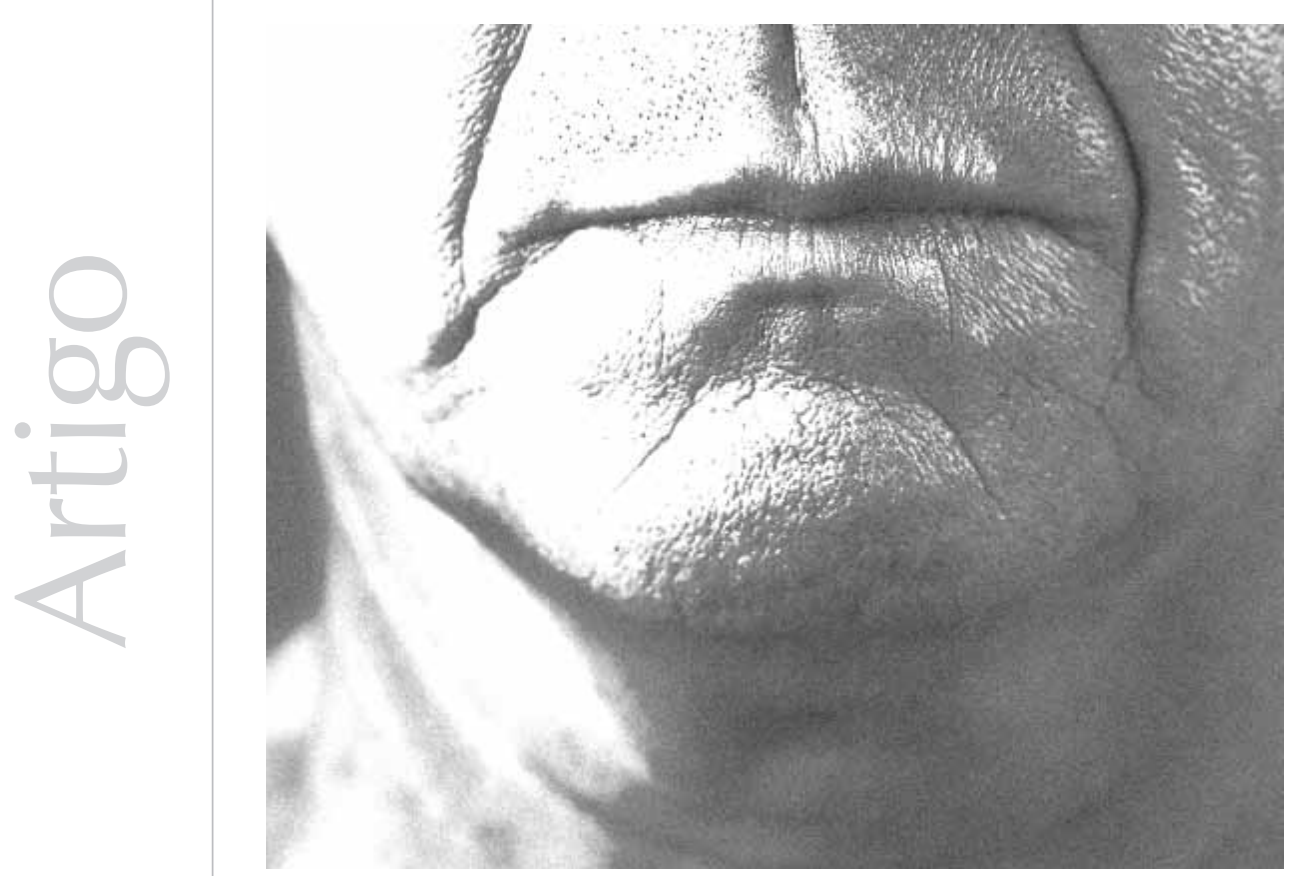
Resumo: Este estudo objetivou conhecer as represe̊ntações sociais do corpo na perspectiva de homens idosos piauienses. Participaram 50 homens, com idade igual ou superior a 60 anos, com média de idade de 72 anos. Utilizou-se como instrumento um questionário sociodemográfico e uma entrevista estruturada com uma questão norteadora acerca das mudanças corporais. A análise dos dados foi realizada por meio do software de análise quantitativa de dados textuais (Alceste). Verificou-se, entre os idosos, uma representação do corpo como sinônimo de saúde, ancorada em uma perspectiva orgânica das mudanças corporais advindas do processo de envelhecimento. Identificou-se que a maioria dos homens adota uma certa impessoalidade com relação ao corpo que não envolve aspectos de autoestima, e que resume a simbologia do corpo aos fatores ligados à saúde, consequência da forma contraproducente de valorização do corpo no contexto psicossocial, no qual se idealizam padrões estéticos ligados à beleza que são agravados pela perda da força física e pela decadência de energia.

Palavras-chave: Corpo. Representação sociais. Idoso. Velhice.

Abstract: This work aimed at knowing the social representations of the body in the senior piauienses' men perspective. 50 men, who were 60 years old or more, with average of 72 years old participated in the research. It was used as instrument a partner-demographic questionnaire and an interview structured with a question concerning the corporal changes. The analysis of the data was made through the software of quantitative analysis of textual data (Alceste). It was verified among the seniors a representation of the body as a synonym of health besed on an organic perspective of the corporal changes that come along with the aging process. It was identified that most of the men adopt an impersonal view regarding the body that doesn't involve self-esteem and that summarizes the simbology of the body to factors connected to health, which is a consequence of the self-defeating way the body in seen the psicossocial context, where idealized aesthetic patterns linked to beauty are worsened by the loss of the physical force and the energetic decadence. Keywords: Body. Social representations. Senior. Old age.

Resumen: Este estudio ha tenido como objetivo conocer las representaciones sociales del cuerpo en la perspectiva de los hombres mayores del Estado de Piauí. Han participado 50 hombres, con edad igual o mayor que 60 años, con un promedio de edad de 72 años. Se ha utilizado como instrumento un cuestionario sociodemográfico y una entrevista estructurada con una cuestión orientadora acerca de los cambios corporales. El análisis de los datos ha sido llevado a cabo a través del software de análisis cuantitativo de datos textuales (Alceste). Se ha observado, entre los ancianos, una representación del cuerpo como sinónimo de salud, basada en una perspectiva orgánica de los cambios corporales oriundos del proceso de envejecimiento. Se ha identificado que la mayoría de los hombres adopta cierta impersonalidad en cuanto al cuerpo que no involucra aspectos de autoestima, y que resume la simbología del cuerpo a los factores que tienen relación con la salud, consecuencia de la forma contraproducente de valoración del cuerpo en el contexto psicosocial, en el cual se idealizan estándares estéticos relacionados a la belleza, que se vuelven más graves por la pérdida de la fuerza física y por la decadencia de energía.

Palabras clave: Cuerpo. Representaciones sociales. Anciano. Vejez.

O processo de envelhecimento é um fenômeno que se caracteriza por sua heterogeneidade, multicausalidade e multifatorialidade. Assim, as mudanças corporais ocorrem ao longo do desenvolvimento humano e são paulatinamente construídas e reconstruídas pela influência dos aspectos psicossociais, históricos e culturais. Tal fato relacionado à corporeidade na velhice assume um simbolismo que pode influenciar diretamente a autoimagem das pessoas idosas e a forma como estas representam o seu processo de envelhecimento.

O aumento do número de idosos no Brasil já se tornou um fato irreversível que tende cada vez mais a se acentuar, sendo esse um fenômeno que se desenvolve de forma progressiva e gradual (Kalache, 1987; Araújo, Coutinho, \& Carvalho, 2005a). De acordo com dados e projeções do Instituto Brasileiro de Geografia e Estatística - IBGE (2010), o Brasil já conta a média considerável de 21 milhões de brasileiros que possuem 60 anos ou mais, o que perfaz cerca de $11,1 \%$ da população. Observou-se que a proporção de pessoas idosas aumentou 5,7\% em $2008 \mathrm{em}$ relação a 2007, e cresceu mais de 23\% nos últimos dez anos.

Há algum tempo, as questões que envolviam o processo de envelhecimento não despertavam 
interesse significativo por parte de estudiosos do desenvolvimento humano (Araújo \& Carvalho, 2004). Tal fato poderia estar relacionado à conotação negativa atribuída a essa etapa da vida, isto é, aos preconceitos e estereótipos fortemente enraizados na cultura ocidental e que prevalecem ainda nos dias atuais. Logo, envelhecer não era considerado um estágio de desenvolvimento e de adaptação, mas de um irremediável decréscimo, no qual não existiria benefícios ou características favoráveis ao desempenho de atividades, mas um declínio da vida adulta que precede a morte (Araújo et al., 2005a; Cupertino, Rosa, \& Ribeiro, 2007; Neri, 2002a).

Os estudos sobre o envelhecimento ganharam impacto a partir do século $X X$, quando a multidimensionalidade e a heterogeneidade da velhice começam a ser reconhecidas como resultado da investigação dos múltiplos determinantes do envelhecimento (Cupertino et al., 2007; Morais, 2009). Neri (2004) salienta que já se nota um cuidado merecido em relação aos idosos na sociedade contemporânea devido ao surgimento de novos paradigmas para a senescência e para o processo de envelhecimento. Porém, foi somente a partir de 1960 que a Psicologia aperfeiçoou a descrição e a elucidação dos fenômenos do envelhecimento, considerando essa fase da vida um processo determinado por fatores genéticobiológicos, psicológicos e socioculturais (Neri, 2002; Resende \& Neri, 2009).

Ainda assim, a velhice é comumente definida como uma época em que o indivíduo passa por muitas perdas, como a diminuição da resistência a doenças, mudanças corporais e a redução da força e da agilidade, isto é, ainda existe um estereótipo do velho como um ser incapaz e improdutivo. Segundo Schneider e Irigaray (2008), mesmo nos dias atuais, com tantos recursos para prevenir doenças e retardar a velhice, ela ainda é temida por muitas pessoas e vista como uma etapa desagradável da vida.
E por que não citar os estereótipos negativos que acabam atribuindo ao processo de envelhecimento adjetivos inadequados, como perdas que desqualificam os idosos; um exemplo já muito rebatido é o que se acha relacionado à diminuição da capacidade de aprender, que era preconizada pelo paradigma mecanicista (Neri, 2002). As perdas cognitivas que fazem parte do processo natural do envelhecimento não ocorrem somente por esse motivo; muitas vezes, por causa da aposentadoria e das mudanças nos papéis sociais, as funções cognitivas, como a memorização, são menos exercitadas (Neri, 2006; Yassuda, Lasca, \& Neri, 2005).

As representações sociais acerca dos idosos acabam por provocar uma não identificação, por parte dos mesmos, com essa etapa da vida, pois grande parte das pessoas com 60 anos ou mais não se vê dessa forma; o idoso é sempre o outro, e a utilização de eufemismos para nomear essa etapa da vida e tudo o que a ela se refere espelha tal fato. Nesse sentido, Goldfarb reflete sobre a forma de experienciar essa fase do desenvolvimento na sociedade moderna: "Parece-me que a velhice, como alguma coisa da ordem do diabólico, não pode ser nomeada sem provocar medo e rejeição" (1998, p. 10).

Há, porém, uma explicação para esse desejo de se esquivar do processo de envelhecimento e de suas formas de expressão: o temor do isolamento, da perda do status familiar, do poder econômico e da participação social como um todo, pois, na sociedade moderna, predomina a valorização do trabalho destinado à produção e à criatividade, tarefa cabível aos mais jovens (Aguiar \& Nascimento, 2005; Santos \& Dias, 2008); além disso, quando pessoas de meia-idade e/ou idosas se encontram empregadas, é comum serem desvalorizadas pelas organizações (Fontes, Neri, \& Yassuda, 2010). 
Yassuda e Abreu (2006) salientam que é comum, ainda que a velhice não seja patológica, um significativo declínio na memória, na atenção, na função executiva e em outras; isso, porém, não pode justificar a frequente desvalorização da condição dos idosos, que inclui certa tendência a representar a velhice a partir de aspectos como perdas, doenças, incapacidades.
Analisando essas questões relativas aos idosos, podemos dizer que são definidas, de acordo com Schneider e Irigaray (2008), conforme os contextos histórico, cultural e ambiental ao qual o idoso pertence, e modificam-se no decorrer do tempo. Nas diversas sociedades tradicionais, a função do idoso estava diretamente relacionada à transmissão dos conhecimentos e das vivências do grupo aos mais jovens; o idoso era uma figura de respeito e de autoridade devido à sabedoria de que era dotado.

O advento da Revolução Industrial, no século XVIII, culminou em uma alteração nas formas de vivenciar esses valores, e a figura do idoso foi restringida ao âmbito da tradição familiar, pois o reconhecimento estaria ligado, a partir de então, à produtividade. A velhice, portanto, passou a ser sinônimo de decadência, de inutilidade:

Na época contemporânea, florescer do século XXI, ao mesmo tempo em que a sociedade potencializa a longevidade, ela nega aos velhos o seu valor e sua importância social. Vive-se em uma sociedade de consumo na qual apenas o novo pode ser valorizado, caso contrário, não existe produção e acumulação de capital. Nessa dura realidade, o velho passa a ser ultrapassado, descartado, ou já está fora de moda (Schneider \& Irigaray, 2008, p. 2)

Ocorreram ainda modificações na maneira de conceber o corpo. Nesse contexto, o ciclo biológico não é o único aspecto ressaltado, pois o corpo assume uma conotação simbólica que resulta das construções sociais, cuja imagem ideal é a da saúde e da beleza associada à juventude (Blessmann, 2004). Isso ocorre porque, através da linguagem, o corpo se apresenta como portador de sentido, em uma condição de signo possível de ser interpretado, já que faz referência a um conjunto representativo mental que vai além da constituição orgânica.
O corpo, em seu significado é, antes de tudo, resultante de fatores socioculturais cuja construção se faz de modo interdependente do meio de interação e reflete aspectos ressaltados em um contexto. Essa autoimagem é reavaliada durante toda a vida conforme a dinâmica do ambiente, e está atrelada a aspectos psicológicos que envolvem a autopercepção (Tessmer, Silva, Pinho, Gazalle, \& Fassa, 2006; Da Motta, 2002). Verifica-se, atualmente, uma valorização de imagens de juventude, saúde e beleza como ideais a serem alcançados, padrões esses difundidos pelos mais diversos meios de comunicação (Santos \& Dias, 2008). Tal modelo reforça a visão antagônica entre juventude e velhice, atividade e passividade.

Yassuda e Abreu (2006) salientam que é comum, ainda que a velhice não seja patológica, um significativo declínio na memória, na atenção, na função executiva e em outras; isso, porém, não pode justificar a frequente desvalorização da condição dos idosos, que inclui certa tendência a representar a velhice a partir de aspectos como perdas, doenças, incapacidades. Isso é, no entanto, contraditório, já que "várias pessoas idosas se mantêm saudáveis, demonstrando que há vários modelos de envelhecimento e de velhice" (Falcão \& Carvalho, 2010, p.12).

Há ainda, na atualidade, uma difusão massificada dos padrões atuais de estética, o que causa no idoso o rebaixamento da autoestima e da qualidade de vida, pois, para ele, a perda da beleza e das características físicas tão valorizadas socialmente é sinal de decrepitude e de finitude. O indivíduo vivencia, portanto, um luto antecipado quando tem uma consciência deturpada relativa à deterioração, já que se vê desprovido de beleza, de saúde, e improdutivo. Ele pensa estar em um processo de declínio, fato que destrói a fantasia de imutabilidade e de imortalidade; nesse sentido, o sofrimento que advém do corpo e do olhar do outro 
Goldman

(2008) salienta

ainda que essa

é a imagem

de homem

adquirida ao

longo de toda uma vida dotada de ação e de instrumentalidade, que são muito valorizadas na fase adulta. tornam o idoso bem mais modesto em suas reivindicações (Goldfarb, 1998; Da Motta, 2002; Maffioletti, 2005).

No Brasil, pesquisas que envolvem a imagem corporal de pessoas com 60 anos ou mais demonstram a visão simplificada e negativa a respeito do próprio corpo, conforme evidenciam Ferreira e Simões (2007) em um estudo realizado no Estado de São Paulo, em que os idosos se representam limitados e doentes, fazendo sempre alusão ao corpo como decaído e desprovido de beleza. O fato de reduzir a velhice ao âmbito físico tem uma repercussão sistemática na qualidade de vida dos idosos, porque essa concepção pode se estender ao comportamento, à personalidade e à identidade, refletindo-se no rol de relações sociais do idoso (Maia, 2008).

A percepção da velhice é muitas vezes encarada de maneira brusca, pois, para muitos idosos, a imagem refletida no espelho muda repentinamente, e, apesar de saberem que é a sua, não podem negar a estranheza que provoca. A imagem da memória é, em geral, idealizada, e há uma falta de reconhecimento da imagem, não do sujeito (Goldfarb, 1998). O indivíduo sabe perfeitamente que é aquela pessoa do espelho, entretanto, não pode evitar o susto.

Com relação às alterações corporais que acompanham a velhice, pode-se destacar a redução da força muscular, que pode fazer com que o idoso enfrente dificuldades para desempenhar as atividades básicas da vida cotidiana. A fraqueza muscular pode levar a consequências ainda mais sérias, como acidentes graves, todavia, Silva, Fossatti e Portella (2007) ressaltam que, mesmo com movimentos e respostas motoras mais lentas, a suscetibilidade a acidentes e quedas está condicionada também a um ambiente físico domiciliar inseguro e a fatores individuais, tais como condições de saúde agravadas por sequelas de acidente vascular cerebral.
O envelhecimento e as mudanças corporais acarretadas pela senectude podem trazer ainda mais consequências para os indivíduos do sexo masculino do que para as mulheres. Isso se deve principalmente a fatores culturais, que cultivam no homem uma postura de receptor da atenção e dos cuidados femininos. Devido a essa falta de estímulo ao hábito do autocuidado, o homem padece na velhice de dificuldades de interação social por não estar acostumado a desempenhar as atividades domésticas.

Uma imagem centrada na atividade e na energia pode gerar ainda nos homens que se encontram na terceira idade uma visão de incapacidade e doença (Sousa \& Cerqueira, 2006). Essa visão provém da forma estigmatizada de conceber a velhice, decorrente de todo um processo sociocultural que faz com que as primeiras experiências se tornem objeto de inquietação, expresso em sentimentos de declínio e de menos valia que são ampliados aos papéis sociais, econômicos e culturais do idoso (Goldman, 2008; Arcuri, Oliveira, \& Ramos, 2004).

Goldman (2008) salienta ainda que essa é a imagem de homem adquirida ao longo de toda uma vida dotada de ação e de instrumentalidade, que são muito valorizadas na fase adulta. Com um envelhecimento estigmatizado, é desenvolvido um sentimento de perda de potencialidade, de enfraquecimento, que é mais frequente na população masculina, já que o envelhecimento feminino vem se modificando nas últimas décadas, conforme demonstra o estudo de Camarano (2003): a última etapa da vida e a viuvez não são mais sinônimos de isolamento e pobreza, mas de atividade.

Diante dessas premissas, o presente artigo possui como objetivo geral verificar e analisar as representações sociais (RS) que os homens idosos possuem a respeito do corpo e das mudanças decorrentes do processo de 
envelhecimento. O conhecimento desses aspectos é importante, porque permite a compreensão de modos compartilhados de pensar, levando-se em conta que as RS não possuem apenas uma base cognitiva, mas correspondem a um processo de elaboração e de difusão de conceitos por meio da cultura, da História, que são compartilhados pelos grupos e que têm implicações comportamentais na vida cotidiana (Moscovici, 2003). Entende-se, portanto, que as palavras utilizadas e a estruturação refletem as representações, já que exprimem asserções morais e o saber do senso comum (Veloz, Nascimento-Schulze, \& Camargo, 1999; Araújo et al., 2005a).

\section{Método}

\section{Locus de investigação}

Este estudo foi realizado em estabelecimentos públicos e privados onde existiam homens idosos na cidade de Parnaíba, localizada na região norte do Estado do Piauí, Brasil.

\section{Participantes}

Participaram 50 homens com idade igual ou superior a 60 anos, escolhidos de forma aleatória, não probabilística, intencional e acidental, em uma zona urbana da cidade de Parnaíba, Pl. A idade dos participantes variou de 60 a 91 anos, com média de idade de 72 anos, dos quais $87 \%$ residem com a companheira e são os provedores financeiros da família, 74\% são aposentados, $60 \%$ recebem mais de dois salários mínimos e 14\% desenvolvem atividades laborais. Para participar da amostra, os participantes deveriam possuir idade igual ou superior a 60 anos e concordar em fazer parte da pesquisa de forma voluntária e anônima, não tendo sido verificada nenhuma resistência e/ou desistência em participar.

\section{Instrumentos}

Foram utilizados como instrumentos para a coleta de dados um questionário com dados sociodemográficos que englobava idade, estado civil, dados referentes à atividade econômica e outros, seguido de uma entrevista estruturada com uma pergunta norteadora: como o senhor observa as mudanças do seu corpo com relação ao envelhecimento? Essa indagação teve o intuito de averiguar as representações que os idosos possuíam acerca das transformações corporais advindas do processo de senescência.

\section{Procedimentos}

Os procedimentos inerentes à realização da coleta de dados deram-se em situação coletiva, e as respostas foram individuais. Inicialmente, contactou-se os idosos em suas residências e em lugares públicos com o intuito de verificar a sua disponibilidade de participar da presente pesquisa. Posteriomente, realizouse a elucidação dos objetivos norteadores do trabalho e a apresentação do Termo de Consentimento aos idosos, em duas vias, para fins de comprovação referentes a padrões éticos. Após uma leitura prévia e o consentimento livre e esclarecido acerca do anonimato e da participação de caráter voluntário, deu-se a aplicação dos instrumentos, realizados por quatro pesquisadores previamente treinados. O tempo médio de aplicação correspondeu a 20 minutos para cada ator social.

\section{Análise dos dados}

No que tange aos dados do questionário sociodemográfico, foram utilizadas estatísticas descritivas para caracterização dos atores sociais. Para a análise dos dados apreendidos através da entrevista estruturada, utilizou-se o software ALCESTE (Análise Lexical por Contexto de um Conjunto de Segmentos de Texto) em sua versão 4.5, que foi desenvolvido na França por M. Reinert (1986, 1990). O 
referido programa, além de permitir uma análise lexical quantitativa que considera a palavra uma unidade, também oferece a sua contextualização no corpus ou entrevista.

Cada entrevista é composta por conteúdos semânticos, que formaram o banco de dados ou corpus analisado pelo Alceste. Realizou-se uma análise hierárquica descendente que permite a análise das raízes lexicais e oferece os contextos em que as classes estão inseridas de acordo com o segmento de textos do corpus da pesquisa (Camargo, 2005).

\section{Resultados e discussão}

O corpus analisado no presente estudo foi constituído por 50 unidades de contexto inicial (uci) ou entrevistas. Foram desconsideradas as palavras que apresentaram frequência inferior a cinco. O dendograma abaixo apresenta as quatro classes das RS do corpo na velhice feitas pelos idosos pesquisados. Na sequência, são ressaltados o título da classe, a quantidade de uci obtidas, as variáveis descritivas e as palavras que obtiveram maior associação com a classe determinada, destacando-se que é levado em conta o coeficiente Qui quadrado obtido na associação.

Ressalta-se que as RS da velhice no Dendograma 1, abaixo apresentado, estão estruturadas em quatro classes: significado atribuído ao corpo, transformações orgânicas no corpo do idoso, sentimentos com relação ao corpo e descrições sobre o corpo na velhice. Serão discutidas, a partir das uci, as classes estruturadas a seguir.

\section{Classe 1:}

Significado

atribuído ao corpo

34 uci $=23 \%$

do total Variáveis

descritivas:

Provedor da família

Casado

Idade: 66-70

Palavras de maior associação:

\begin{tabular}{|lc|}
\hline Palavras & Khi2 \\
Viver & 13 \\
Velhice & 13 \\
Muita & 9 \\
Doença & 9 \\
Do & 8 \\
Fico & 7 \\
\hline
\end{tabular}

\section{Classe 2:}

Transformações no corpo do idoso

14 uci $=9 \%$ do total Variáveis descritivas:

Solteiro

Provedor da família

Casado

Idade: 71-80

Palavras de maior associação:

\begin{tabular}{|ll|}
\hline Palavras & Khi2 \\
Perna & 28 \\
Gente & 24 \\
Vai & 11 \\
Sente & 11 \\
Dor & 8 \\
Diferença & 8 \\
\hline
\end{tabular}

Classe 4:

Descrições sobre o corpo a partir das transformações orgânicas

74 uci $=50 \%$ do total Variáveis descritivas: Não provedor da família

Palavras de maior associação:

Palavras de maior associação:

\begin{tabular}{|lc|}
\hline Palavras & Khi2 \\
Coisa & 22 \\
Faz & 12 \\
Cansaço & 11 \\
Sinto & 10 \\
Posso & 6 \\
\hline
\end{tabular}

$\begin{array}{lc}\text { Palavras } & \text { Khi2 } \\ \text { Jovem } & 8 \\ \text { Normal } & 8 \\ \text { Acho } & 7 \\ \text { Mudanças } & 7 \\ \text { Limitações } & 6 \\ \text { Pra } & 5 \\ \text { Vou } & 5 \\ \text { Parte } & 5\end{array}$

Dendograma 1. Distribuição das classes nas representações sociais do corpo na velhice $(n=50)$ 


\section{Classe 1: Significado atribuído ao corpo}

As cognições que compõem a percepção do corpo, conforme as entrevistas, incluem não só as modificações físicas, o florescimento de doenças concernentes ao corpo (corpodoença) mas também as visões positivas no âmbito geral da velhice, possibilitadas pelo avançar da idade.

A classe 1 é composta por 34 uci, que constituem $23 \%$ de explicação do total, sendo, dessa forma, significativa quanto às representações encontradas de maneira geral. Os idosos ligados a essa classe apresentam, em sua maioria, idade que vai de 66 a 70 anos, são provedores econômicos e residem com as companheiras. Foram apreendidos nessa classe, dentre outros, conteúdos referentes à falta de perspectivas futuras devido às perdas referentes à idade e à impossibilidade de o corpo realizar tarefas comuns em outras épocas do ciclo de vida, ou seja, à diminuição da atividade e da agilidade.

Nesse âmbito, os conteúdos da análise lexical apontam ainda nessa classe uma dissociação corpo-mente, pois tanto há referência ao corpo doente, incapacitado, como à mente que se exercita e que, assim, é saudável. Conforme Blessman (2004), essa referência a corpo velho e mente saudável indica uma dissociação, e posterior incompreensão, da unidade do ser humano, que é baseada em uma concepção cartesiana; mais do que isso, justifica pensamentos autopreconceituosos, nos quais há uma fuga do ser velho, com alusão à jovialidade da mente. Ideias direcionadas para a necessidade de cuidados e precauções também foram verificadas nessa classe, e estão associadas à manutenção de um equilíbrio necessário ao corpo já desgastado, conforme o relato a seguir:

A gente começa a tomar medicações; eu tomo para a próstata, visão, hipertensão.
Fisicamente, numa escala de zero a dez, eu estou em um, com relação à velhice (...) com relação à mente, eu estou ótimo, porque eu sempre me exercito (...) Quanto ao corpo, minha barriga cresceu (...) Nada é como antes (Entrevista 20).

Os relatos estão intimamente ligados ao que é comum aos homens dessa faixa etária conforme sua percepção: a negatividade da velhice a partir da perda da força física e a falta de habilidade para a produção e o trabalho típicos da sociedade capitalista, o que corrobora outras pesquisas na área, como a de Araújo, Coutinho e Santos (2006).

O envelhecimento, conforme expõe Goldman (2008), apresenta-se como dinâmico, ou histórico; dessa forma, a marca, o símbolo do passado, é transferido para o presente, havendo sua reprodução e novamente invenção e vivência de novas situações individuais e grupais no cotidiano. Assim, as vivências comuns de uma comunidade podem gerar representações sociais aproximadas, como no caso da referência ao corpo, que está atrelada à força física, não recebendo as mudanças na aparência valor de destaque.

Há, todavia, aspectos positivos ligados ao suporte social, como no caso da convivência com amigos a partir do aumento de tempo disponível com o término das atividades laborais: "(...) Aumentou a convivência com os amigos. Antes eu corria, agora estou mais calmo". (Entrevista 40). Dentre outros fatores, isso se deve à abertura de novos espaços, para que diversas experiências bem sucedidas de envelhecimento possam ser vividas coletivamente. Como exemplo, temse os grupos de convivência, que propiciam o exercício de cidadania aos idosos além de fortalecer as suas potencialidades e de melhorar a sua autoimagem, o que é imprescindivel para manter equilibradas as relações pessoais e intrapessoais relevantes a um bom envelhecimento (Veloz, et al., 1999; Queiroz \& Neri, 2005; Araújo et al., 2005a). 
Ainda quanto à significação dada ao corpo, foram encontradas mais possibilidades no que tange à autoestima, fato apreciável dadas as pequenas perspectivas que, em especial, os homens idosos atribuem ao corpo, resumindo muitas vezes sua percepção a corpo-cansado, corpo-improdutivo, corpo-fraco. A entrevista a seguir expressa essa forma positiva de ver a velhice, aliando ainda a manutenção do bem-estar a precauções necessárias:

Na juventude, o meu corpo era magrinho; já com o passar do tempo, o corpo ficou foi melhor, fiquei mais cheio, tô achando bom, porque eu queria ter mais corpo, então não acho tão ruim a idade, o negócio é não ser extravagante com as coisas, porque tem que saber que com a idade o corpo não aguenta mais tudo (Entrevistado 40).

Verifica-se, dessa forma, na classe 1 , que os conteúdos da análise hierárquica tornam nítida a heterogeneidade presente na forma de vivenciar a velhice do ponto de vista corporal. A ligação direta com as classes 2 e 3 confirma as disposições demonstradas. Sentimentos, pensamentos e perspectivas são interdependentes de aspectos psicossociais, tornando positivas, negativas e/ou sendo sinônimos de novas formas de vivências.

\section{Classe 2: Transformações orgânicas no corpo do idoso}

A segunda classe da análise hierárquica aqui aplicada abarca 9\% do total das unidades de contexto elementar (14 uce) das 50 entrevistas. A classe indica RS do corpo menos compartilhadas que as demais, portanto, com pequeno poder explicativo. Os entrevistados dessa classe são, em sua maioria, casados e/ ou separados ou divorciados, são provedores econômicos e estão inseridos em um intervalo de idade de 71 a 80 anos.

As RS do corpo indicadas por essa classe delineiam noções especialmente ligadas à naturalização da velhice no que concerne à perda da saúde e ao surgimento de doenças, bem como maior vulnerabilidade orgânica, o que se acha refletido nas palavras que a estruturam: pernas, vai, dor, sente, diferença. Os aspectos relativos ao corpo, nesse âmbito, demonstram um realce na questão da saúde, perdida com a velhice, já que os homens entrevistados pertencentes a essa classe expõem diversos problemas que surgiram e que são inerentes à velhice:

\begin{abstract}
“(..) De acordo com a época que a gente vai passando, vai sentindo diferenças como o cansaço e outros problemas de saúde" (Entrevistado 18). "Sou muito ruim dos ouvidos, também enxergo pouco, eu também tive que operar de vesícula, porque tive problemas. Eu me sinto mal (...) Eu não tô prestando mais (Entrevistado 02).
\end{abstract}

Arcuri et al. (2004) enfatizam que o registro corporal geralmente aplicado às pessoas com idade avançada inclui cabelos brancos, calvície, rugas e enrijecimento. Apesar de depender da idade biológica, tais características e outras, como integridade das artérias, coração gasto e pulmões congestionados, não são somente relacionados à velhice, pois os demais sujeitos também estão vulneráveis a esses problemas; além disso, os ganhos com a velhice, que incluem sabedoria e experiência, podem sobrepor-se às perdas, o que interdepende dos valores e conceitos estigmatizados.

É assinalado ainda o desgaste natural interno e externo do corpo, não havendo, porém, referência a questões ligadas à beleza física, de tal forma que a identidade pessoal aparece sem o reconhecimento do próprio corpo: "(...) com o tempo, vai mudando, a cabeça vai ficando mais branca, o cabelo vai caindo aos poucos, vai aparecendo as rugas, vai tudo encolhendo" (Entrevistado 15).

Como assinalam Veloz et al. (1999), a valorização do corpo vai de encontro a uma ideologia comum nos meios de comunicação social, que permite o enraizamento de um contraponto utilizado por pessoas idosas ou ditas diferentes do padrão estético corporal 
socialmente proposto e apreciável, comum em situações de comparação social. Essa ideologia é socialmente aceita, devendose salientar que as RS são construídas, reconstruídas e compartilhadas nos quadros da convivência quotidiana.

O discurso a seguir torna perceptível o desconhecimento da multifatoriedade durante o processo de envelhecimento, com o aparecimento de enfermidades e de outras complicações que impossibilitam muitas vezes o bem-estar das pessoas idosas, sendo a terceira idade tratada por muitos como sinônimo de doença e de fraqueza, o que faz parte de uma espécie de destino inalterável: "A saúde da gente fica mais frágil e a gente perde a energia. A gente tem que sentir um pouco a velhice, pois é normal" (Entrevistado 18).

A literatura demonstra que as imagens dos idosos tendem a ser negativas, mas estes também citam aspectos positivos e neutros, sendo que as suas imagens mais comuns se referem a uma fase normal, que inclui desânimo, vulnerabilidade e incapacidade (Sousa \& Cerqueira, 2006).

\section{Classe 3: Sentimentos com relação ao corpo}

Essa classe foi estruturada com 22 uci, o que corresponde a $14 \%$ do total. Os conteúdos fizeram referência a uma RS centrada fundamentalmente em limitações quando se compara a terceira idade com a juventude (sinto), em sentimentos de impotência (posso - aqui significando não poder), cansaço, coisa. Os participantes que produziram léxicos característicos dessa segunda classe são separados do cônjuge. De acordo com o dendograma, essa foi a terceira classe em ordem de importância de significado, e apresenta ainda uma ligação direta com a classe 2, que trata das mudanças orgânicas.
Nas unidades de contexto elementar da presente classe, pode-se verificar a associação do corpo com as impossibilidades do dia a dia. O cansaço e a dor são exemplos que revelam manifestação de normalidade quanto ao corpo, como no caso das dores, consideradas manifestações naturais (Uchôa, Firmo, \& Lima-Costa, 2002).

Percebe-se ainda, nessa classe, a predominância de conteúdos ligados à perda das condições de autonomia relacionadas ao trabalho, ao esforço físico, quando comparados à juventude, resultado das limitações de saúde e/ou da precaução dos cuidadores: "(...) Hoje em dia fico pensando que não posso mais trabalhar, porque meu filho não deixa; ele acha que eu não posso mais, e tem medo de acontecer alguma coisa comigo (Entrevista 10). (...) A gente não dorme mais direito, não é mais quando a gente era novo. Tem uma mudança na energia" (Entrevista 21).

A juventude, nesse âmbito, aparenta ser uma fase do ciclo de vida com maiores possibilidades do que a velhice, sendo aquela sinônimo de saúde. Nesse sentido, crescem as novas tecnologias para rejuvenescer, que contribuem para propiciar uma espécie de equilíbrio nas relações do indivíduo com o coletivo e que representam uma espécie de amuleto contra as dificuldades da vida e um meio de alcançar objetivos (Sant'anna, 2006).

Para Maia (2008), é ainda bastante comum a presença do modelo biomédico dominante quando há definição do envelhecimento, considerando-o exclusivamente em termos de declínio da idade adulta, com a presença de patologia, fazendo com que o envelhecimento seja uma espécie de doença a ser tratada dado o alto grau de negatividade que lhe é atribuído. Dessa forma, percebe-se o quão extensa é a dificuldade em lidar com a velhice e com os imperativos que a ela se aplicam devido às atitudes e crenças que 
erroneamente nomeiam essa etapa (Neri \& Jorge, 2006).

\section{Classe 4: Descrições sobre o corpo na velhice}

Finalmente, a quarta classe da análise hierárquica que aqui foi empregada envolve $50 \%$ do total, perfazendo 74 unidades de contexto elementar. Essa quarta RS exibe um alto poder explicativo pela representatividade na análise semântica. Os homens idosos objetivaram suas descrições especialmente nas incapacidades advindas das modificações orgânicas do corpo. Os indivíduos não provedores da família retrataram bastante essa classe.

A imagem do homem velho geralmente se associa a incapacidade e dependência, especialmente pelo fato de ele desenvolver, durante a vida, a imagem social centrada em atividade e energia, sendo a questão da perda da força muscular e das habilidades, portanto, da competência funcional, mais representativa desses sujeitos (Sousa \& Cerqueira, 2006).

As representações estão expressas nas seguintes palavras, que refletem as novas formas de organização a partir das mudanças que a idade ocasionou: jovem (expressando comparação da fase atual com aquela), normal, acho, mudanças, limitações, pra, parte (expressando segmentação corpomente).

As impossibilidades ficam ainda mais nítidas devido ao término das atividades laborais, fazendo com que os homens, ao adentrar a fase improdutiva, na visão capitalista, permaneçam algumas vezes dependentes de outros familiares, o que torna a terceira idade um período de impedimentos e de pouca autoestima: "Fiquei fraco; quando eu era mais jovem, tinha disposição para o trabalho. $O$ corpo muda com a velhice. Quando era novo, trabalhava muito, o corpo não tem mais tanta disposição" (Entrevista 33).

Dessa forma, é preciso estar atento ao papel dos familiares e das instituições no que tange à vitimação do idoso, pois, muitas vezes, o cuidado acaba sendo confundido com superproteção, minimizando a sua autonomia e a sua independência, tão reivindicadas em etapas anteriores da vida (Neri \& Jorge, 2006). Nesse sentido, Vilarino e Lopes (2008) destacam que, para muitos idosos, tanto homens quanto mulheres, ter condição para o trabalho é sinônimo de saúde e de melhor qualidade de vida, levando-se em conta o fato de que essa identidade de trabalhador está intimamente ligada ao cotidiano dessas pessoas durante toda uma vida, e constitui, portanto, uma frustração o fato de não mais haver possibilidade de realizar o trabalho nessa fase da vida:

A gente começa a sentir como primeiro sintoma a diminuição da velocidade no trabalho, come menos, porque sente menos apetite, fica econômico (...) Fisicamente não tenho mais resistência, tem uma intensificação da fragilidade do corpo, ele fica mais sensível a doenças (Entrevista 23).

Faleiros (2008) contextualiza tais ideias enfatizando que, na modernidade, a classificação das pessoas se faz pela referência à produção e à não produção, especialmente no caso dos homens, permeando, portanto, uma visão do envelhecimento como momento improdutivo, valor adotado por essa sociedade fundamentada na exploração do trabalho que estigmatiza a ausência de trabalho ao atrelá-la à indolência, ao vício e ao parasitismo.

No que se refere à manutenção da qualidade de vida, Ribeiro e Yassuda (2007) observam que tanto podem influir fatores intrínsecos como extrínsecos, estes últimos referentes a controle de peso, hábito de fumar e engajamento social; de alguma forma, são 
determinantes para a condição de vida das pessoas, sendo dependentes de escolhas e passíveis de alteração.

Observa-se que, na presente investigação, as RS dos homens idosos sobre as transformações corporais foram ancoradas em uma perspectiva orgânica, bem como em fatores relacionados à funcionalidade que estas podem acarretar: menor autonomia e independência desses idosos. Por outro lado, não foi verificada nenhuma associação entre as modificações corporais, com a estética física demonstrando que, para os homens, as modificações corporais possivelmente não se correlacionam diretamente com o desejo do corpo juvenil.

\section{Considerações Finais}

A análise dos conteúdos obtidos permitiu verificar a forma com que os homens idosos entrevistados representam socialmente seu corpo, partindo de um ponto de vista biológico ao associá-lo à incapacidade gerada pela perda da força muscular, da saúde, a partir da chegada da velhice que, na maioria das vezes, é visualizada de forma negativa.
Percebeu-se ainda que a aparência física não constitui um fator de importância para os idosos, não tendo sido evidenciada na maior parte das vezes. As mudanças físicas são tratadas de forma naturalizada. Atitudes positivas frente ao envelhecimento foram, porém, ressaltadas, e envolveram o aumento do círculo social aliado ao tempo disponível.

Verifica-se, com isso, que, apesar da prevalência do pensamento biomédico, houve acréscimo de novas características nas RS, o que pode ser resultado do crescente número de idosos na população e do consequente investimento nas políticas de assistência ao idoso, fazendo com que as ideias relacionadas consigo mesmo e com a idade em geral sejam modificadas e tratadas como uma fase do desenvolvimento semelhante às demais.

Espera-se que esta investigação possa fornecer subsídios para discussão e reflexão acerca do estado atual da arte sobre a população idosa, para que sejam fomentadas e implementadas políticas públicas de saúde e psicossociais com o escopo de oferecer melhores condições de vida aos homens idosos, desenvolvendo e incentivando um envelhecimento autônomo. 


\section{Referências}

\section{Ludgleydson Araújo}

Psicólogo, Doutorando em Psicologia e Saúde pela Universidad de Granada - Espanha, Mestre em Psicologia Social, Especialista em Gerontologia pela UFPB, Professor Assistente III do Departamento de Psicologia da Universidade Federal do Piauí -UFPI (Campus Ministro Reis Velloso - Parnaíba/PI),

E-mail: ludgleydson@yahoo.com.br

\section{Elba Celestina do Nascimento Sá}

Bolsista PIBIC/CNPq, Graduanda em Psicologia pela Universidade Federal do Piauí -UFPI (Campus Ministro Reis Velloso - Parnaíba/PI).

E-mail: elbacns@hotmail.com

\section{Edna de Brito Amaral}

Bolsista PIBIC/CNPq, Graduanda em Psicologia pela Universidade Federal do Piauí - UFPI - Campus Ministro Reis Velloso - Parnaíba/PI.

E-mail: ednabamaral@gmail.com

\section{Endereço para envio de correspondência:}

Universidade Federal do Piauí/ Departamento de Psicologia/ Campus Ministro Reis Veloso, Av. São Sebastião, 2819, Parnaíba/PI - Brasil CEP. 64202-020

Recebido 30/1/2010, 1a Reformulação 24/1/2011, Aprovado 5/5/2011.

Aguiar, M. G. G., \& Nascimento, M. A. A. (2005). Saúde, doença e envelhecimento: representações sociais de um grupo de idosos da Universidade Aberta à Terceira Idade (UATI) - Feira de Santana-BA. Textos sobre envelhecimento, 8(3). Recuperado em 12 novembro 2009 de http://www. unati.uerj.br

Araújo, L. F., \& Carvalho, V. A. M. (2004). Velhices: estudo comparativo das representações sociais entre idosos de grupos de convivências. Textos sobre Envelhecimento, 1(6), 57-75.

Araújo, L. F., \& Carvalho, V. A. M (2005). Velhices. Aspectos socio-históricos e psicológicos da velhice. Revista de Humanidade, 6(13), 1-9.

Araújo, L. F., Coutinho, M. P. L., \& Carvalho, V. A. M. (2005a). Representações sociais da velhice entre idosos que participam de grupos de convivência. Psicologia: Ciência e Profissão, 25(1), 118-131.
Araújo, L. F., Coutinho, M. P. L., \& Santos, M. F. (2006). O idoso nas instituições gerontológicas: um estudo na perspectiva das representações sociais. Psicologia \& Sociedade, 18(2), 89-98.

Arcuri, I., Oliveira, P. P., \& Ramos, V. (2004). Momentos do corpo: corpo movimento, corpo emoção. Revista Kairos, 7(1), 137-149

Blessmann, E. J. (2004). Corporeidade e envelhecimento: o significado do corpo na velhice. Estudos Interdisciplinares do Envelhecimento, (6), 21-39.

Camarano, A. A. (2003). Mulher idosa: suporte familiar ou agente de mudança? Estudos Avançados, 17(49), 35-63.

Camargo, B. V. (2005). Alceste: um programa informático de dados quantitativos textuais. In A. S. P. Moreira, J. C. Jesuíno, \& B. V. Camargo (Orgs.), Perspectivas teórico-metodológicas em representações sociais (pp. 511-539). João Pessoa, PB: EdUFPB. 
Cupertino, A. P. F. B., Rosa, F. H. M., \& Ribeiro, P. C. C. (2007), Definição de envelhecimento saudável na perspectiva de indivíduos idosos. Psicologia: Reflexão Crítica, 20(1), 81-86.

Da Motta, A. B. (2002). Envelhecimento e sentimento do corpo. In M. C. S. Minayo, \& C. E. A. Coimbra (Orgs.), Antropologia, saúde e envelhecimento (pp. 37-50). Rio de Janeiro: Fiocruz.

Falcão, D. V. S., \& Carvalho, I. S. (2010). Idosos e saúde mental: demandas e desafios. In D. V. S. Falcão, \& L. F. Araújo (Orgs.), Idosos e saúde mental (pp. 11-31). Campinas, SP: Papirus.

Faleiros, V. (2008). O direito humano ao envelhecimento e o impacto nas políticas publicas. In A. A. A. Santos, A. L. S. Castro, M. C. B. Veras, D. C. Lopes, A. L. Neri, D. C. Goldfarb et al. (Orgs.), Envelhecimento e subjetividade: desafios para uma cultura de compromisso social. (pp. 63-77). Brasília, DF: Conselho Federal de Psicologia.

Ferreira, L., \& Simões, R. M. R. (2006). Traços da imagem corporal do idoso asilado. In IV Mostra Acadêmica UNIMEP. Piracicaba, SP.

Fontes, A. P., Neri, A. L., \& Yassuda, M. S. (2010). Enfrentamento de estresse no trabalho: relações entre idade, experiência, autoeficácia e agência. Psicologia: Ciência e Profissão, 30 (3), 620-633.

Goldfarb,D.C.(1998). Corpo, tempo e envelhecimento. São Paulo: Casa do Psicólogo.

Goldman, C. (2008). Envelhecimento e subjetividade. In A. A. A Santos, A. L. S. Castro, M. C. B. Veras, D. C. Lopes, A. L. Neri, D. C. Goldfarb et al.(Orgs.), Envelhecimento e subjetividade: desafios para uma cultura de compromisso social (pp. 17-23). Brasília, DF: Conselho Federal de Psicologia.

Instituto Brasileiro de Geografia e Estatística - IBGE. (2010). Rio de Janeiro. [CD-ROM].

Kalache, A. (1987). Envelhecimento populacional no Brasil: uma realidade nova. Revista de Saúde Pública, 21(3), 200-210.

Maffioletti, V. L. R. (2005). Velhice e família: reflexões clínicas. Psicologia: Ciência e Profissão, 25(3), 336-351.

Maia, G. F. (2008). Corpo e velhice na contemporaneidade. Estudos e Pesquisas em Psicologia, 3(8), 704-711. Recuperado em 30 de outubro de 2009 de http://pepsic.bvs-psi.org.br/.

Minayo, M. C. S. (2002). Envelhecimento e saúde: experiência e construção cultural. In C. Junior (Org.), Antropologia, saúde e envelhecimento. Rio de Janeiro: Fiocruz.

Morais, O. N. P. (2009). Grupos de idosos: atuação da psicogerontologia no enfoque preventivo. Psicologia: Ciência e Profissão, 29(4), 846-855.

Moscovici, S. (2003). Representações sociais: investigações em psicologia social. Petrópolis, RJ: Vozes.

Néri, A. L. (2002). Teorias psicológicas do envelhecimento. In E. V. Freitas, L. Py, A. L. Neri, F. A. X. Cançado, M. L. Gorzoni, \& S. M. Rocha (Orgs.), Tratado de geriatria e gerontologia (pp. 32-46). Rio de Janeiro: Guanabara, Koogan.

Néri, A. L. (2002a). Bienestar subjetivo en la vida adulta y en la vejez: Rumbo a una psicologia positiva en América Latina. Revista Latinoamericana de Psicologia, 34(1, 2), 55-74.

Neri, A. L. (2006). Envelhecimento cognitivo. In E. V. Freitas, L. Py, F. A. X. Cançado, J. Doll, \& M. L. Gorzoni (Orgs.), Tratado de geriatria e gerontologia (pp. 1236-1244). Rio de Janeiro: Guanabara Koogan.

Neri, A. L., \& Jorge, M. D. (2006). Atitudes e conhecimentos em relação à velhice em estudantes de educação e de saúde: subsídios ao planejamento curricular. Estudos de Psicologia 23(2), 127-138
Neri, A. L. (2004) Contribuição da psicologia ao estudo e à intervenção no campo da velhice. Revista Brasileira de Ciências do Envelhecimento Humano, 1(1), 69-80.

Queiroz, N. C., \& Neri, A. L. (2005). Bem-estar psicológico e inteligência emocional entre homens e mulheres na meia idade e na velhice. Psicologia: Reflexão e Crítica, 18(2), 292-299.

Reinert, M. (1986). Un logiciel d'analyse lexicale: ALCESTE. Les Cahiers de l'Analyse des Données, 4, 471-484.

Reinert, M. (1990). Alceste: Une methologie d'analyse des données textualles et une application. In A. G. Neval Bulletin de Méthodologie Sociologique, 26, 24-54.

Resende. M. C., \& Neri, A. L. (2009). Ajustamento psicológico e perspectiva de velhice pessoal em adultos com deficiência física. Psicologia em Estudo, 14(4), 767-776.

Ribeiro, P. C. C., \& Yassuda, M. S. (2007). Cognição, estilo de vida e qualidade de vida na velhice. In A. L. Neri, Qualidade de vida na velhice: enfoque multidisciplinar (pp. 189-205). Campinas, SP: Editora Alínea.

Sant'anna, D. B. (2006). Entre o corpo e os incorporais. Velhices: reflexões contemporâneas (pp. 101-112). São Paulo: SESC, PUC.

Santos, I. E., \& Dias, C. M. S. B. (2008). Homem idoso: vivência de papéis desempenhados ao longo do ciclo vital da família. Aletheia, 27(1), 98-110.

Schneider, R. H., \& Irigaray, T. Q. (2008). O envelhecimento na atualidade: aspectos cronológicos, biológicos, psicológicos e sociais. Estudos de Psicologia, 25(4), 137-149.

Silva, C. A., Fossatti, F., \& Portella, M. R. (2007). Percepção do homem idoso em relação às transformações decorrentes do processo do envelhecimento humano. Estudos Interdisciplinares do Envelhecimento, (12), 111-126.

Sousa, L., \& Cerqueira, M. (2006). Influência do gênero nas imagens da velhice. Revista Kairós, (2), 69-86.

Tessmer, C. S., Silva, M. C., Pinho, M. N., Gazalle, F. K. \& Fassa A. G. (2006). Insatisfação corporal em frequentadores de academia. Revista Brasileira de Ciência e Movimento, 14(1), 7-12.

Uchôa, E., Firmo, J. O. A., \& Lima-Costa, M. F. F. (2002). Envelhecimento e saúde: experiência e construção cultural. In M. C. S. Minayo, \& C. E. A. Coimbra Jr. (Orgs.), Antropologia, saúde e envelhecimento (pp. 25-35). Rio de Janeiro: Editora Fiocruz.

Veloz, M. C., Nascimento-Schulze, C. M., \& Camargo. B. V. (1999). Representações sociais do envelhecimento. Psicologia Reflexão e Crítica, 12(2), 479-501.

Vilarino, M. A. M., \& Lopes, M. J. M. (2008). Envelhecimento e saúde nas palavras de idosos de Porto Alegre. Estudos Interdisciplinares do Envelhecimento, 13(1), 63-77.

Yassuda M. S., Lasca, V. B., \& Neri, A. L. (2005). Meta-memória e auto-eficácia: um estudo de validação de instrumentos de pesquisa sobre memória e envelhecimento. Psicologia: Reflexão e Crítica, 18(1), 78-90.

Yassuda, M. S., \& Abreu, V. P. S. (2006). Avaliação cognitiva em gerontologia. In E. V. Freitas, L. Py, A. L. Neri, F. A. X. Cançado, M. L. Gorzoni, \& S. M. Rocha (Orgs.), Tratado de geriatria e gerontologia (pp. 1252-1259). Rio de Janeiro: Koogan. 